Revista de Antropología Social

ISSN: 1131-558X

http://dx.doi.org/10.5209/RASO.61860

\title{
Parejas del mismo sexo: una reflexión de carácter interdisciplinar
}

Gallego, M. Gabriel; Jaramillo, A. Claudia Patricia; Vasco Alzate, José Fernando; Uribe, A. Juana. 2017. Develar la diversidad familiar: parejas del mismo sexo en el Eje Cafetero Colombiano. Manizales: Universidad de Caldas.

El libro es resultado de un proceso de investigación realizado en la región del Eje Cafetero colombiano ${ }^{1}$, por un equipo de docentes -investigadores de la Universidad de Caldas del grupo de investigación "Género, sexualidades y reconocimiento», reconocido y clasificado por COLCIENCIAS. El texto es una invitación a reflexionar sobre la diversidad familiar en clave de parejas del mismo sexo, en un contexto localizado, situado. Es un trabajo que rompe directamente con la representación que históricamente se ha construido frente a la estructuración de relaciones de pareja bajo los principios morales de la religión, marcador de identidad de la región cafetera colombiana, que vigila los comportamientos de los individuos en el ámbito público y privado, para dar cumplimiento a lo establecido por el modelo familiar «religioso/ legal» monogámico, indisoluble y de mutua fidelidad: la familia nuclear patriarcal, ámbito naturalizador de la heterosexualidad y lugar desde el cual se proyectan las parejas del mismo sexo y la homoparentalidad como escenarios inviables, abyectos, impensables e irrepresentables.

En Colombia, y específicamente en el eje cafetero, el emparejamiento entre personas del mismo sexo solo aparece narrado en los años 80 del siglo XX (Galvis, 2014), resultado de procesos sociales y políticos que han demandado su reconocimiento y son vigentes en la actualidad. Socialmente, a través de los movimientos sociales que han luchado por el reconocimiento de los derechos de estas parejas, como está documentado en la prensa escrita local y nacional. A nivel jurídico, a partir de las diferentes sentencias de la Corte Constitucional y la Corte Suprema de Justicia que amparan y protegen los derechos de las parejas del mismo sexo: matrimonio y adopción igualitaria y derechos patrimoniales. Políticamente, a través de organizaciones sociales que han desarrollado acciones colectivas para la reivindicación y reconocimiento de sus derechos como familia. Finalmente, en el plano individual y de agencia, a través del establecimiento de la corresidencia como unidades domésticas diferenciadas socialmente. Este último hecho lo reconoce Gallego y su equipo, como uno de los marcadores para nominar al emparejamiento entre personas del mismo sexo corresidente y la homoparentilidad como un hecho sociológico reciente; el segundo sería la visibilidad pública y su colectivización.

A pesar de estos avances normativos en Colombia, y en buena parte de los países de la cultura occidental, frente a la titularidad de derechos hacia las parejas del

1 Hace referencia a una región geógrafica, cultural y económica conformada por los departamentos de Caldas, Risaralda, Quindio y el norte del Valle con sus ciudades capitales: Manizales, Pereira, Armenia y Cartago. Se caracteriza porque en los primeros renglones de su economía está la producción, transformación y comercialización del café. 
mismo sexo, estas se siguen enfrentando a lenguajes excluyentes, señaladores y violentos desde el ámbito religioso, político y de interacciones cotidianas. Este tipo de situaciones acaecidas en pleno siglo XXI, nos deben llevar a la reflexión frente a la necesidad de «promover un leguaje inclusivo y de respeto que permita nombrarlas, darle contenido sustantivo propio» (Gallego y Vasco, 2017).

La investigación que derivó en el libro Develar la Diversidad Familiar tiene como objeto la comprensión del emparejamiento entre personas del mismo sexo desde una perspectiva biográfica, lo cual es novedoso, interesante y útil en el campo de los estudios de familia, ya que permitió reconocer el fenómeno y su configuración en el tiempo individual, social e histórico, en términos de trayectorias y transiciones como ejes organizadores del análisis del curso de vida de los hombres y mujeres con prácticas homoeróticas participantes del estudio -708 en total-. En este sentido, la tesis que guió la investigación fue la existencia de «un efecto de cohorte en la construcción de las biografías sexuales de los varones y las mujeres con prácticas homoeróticas, manifestado en cambios en la forma de construir el deseo y la vivencia de su sexualidad, así como en los modos de gestionar el emparejamiento con alguien de su mismo sexo» (p. 22).

El reconocimiento de la sexualidad como un constructo histórico, maleable y deslindado de la procreación, desinstitucionaliza el modelo único de familia nuclear, para dar pie a modelos familiares y formas de organización de la vida íntima plurales, diversos, que en este caso particular corresponden a lo que conocemos hoy como diversidad familiar, que es el centro de análisis, reflexión y debate del libro. Por tanto, retomando a Gallego en su libro Demografía de lo otro. Biografías sexuales y trayectorias de emparejamiento entre varones en la ciudad de México, se desestructura la tríada de prestigio para definir familia: heterosexualidad, parentesco y corresidencia. Lo que pone en un estado de incertidumbre la misma definición de lo que es y no es una familia. No obstante, y a pesar de la vacilación, se reconoce, con Lluis Duch y Joan-Carles Melich (2009), que familia es la primera y más importante estructura de acogida donde tienen lugar las trasmisiones y aprendizajes más decisivos para el trayecto biográfico de los seres humanos, y suple tres necesidades básicas: encontrar apoyo, estar bajo la autoridad de alguien que orienta y ser protagonista de su propio proyecto de vida personal bajo el principio de la libertad.

Por tanto, es importante recordar lo planteado por Beck y Beck (2001) en el sentido de que hoy debemos pensar la familia como una experiencia humana que se construye de manera diferente, diversa y politizada. Se está frente a la emergencia de nuevas organizaciones familiares que hacen evidente la articulación entre viejos y nuevos modelos de familia, resultado de los procesos de modernización y modernidad tardía, en los cuales se ha roto con la dicotomía público-privado y con la concepción de la sexualidad, que es ahora una dimensión de la personalidad individual, del libre albedrío, que permite prácticas que en el pasado reciente eran condenadas y que hoy se llevan a cabo de manera autónoma por parte de hombres y mujeres en su intimidad o en el ámbito público.

Adentrarnos en la esencia del libro nos permite develar la cotidianidad de las parejas del mismo sexo en términos del ejercicio de la paternidad y la maternidad, las trayectorias, duraciones y contextos del emparejamiento y, por último, la corresidencia y la vida doméstica de estos hombres y mujeres que conviven bajo un modelo de pareja y conforman unidades domésticas y hogares independientes. Con respecto a la paternidad y maternidad, los autores plantean que reivindicar su ejercicio por parte 
de hombres y mujeres que asumen una identidad gay, lésbica o trans, es un ejercicio de contracultura, en tanto reclamar el derecho a ejercerla se valora socio-culturalmente como incompatible con la orientación sexual manifiesta; en otras palabras, hacer pública la orientación sexual pareciera que actuara como una castración social del ejercicio parental. Reclamar ser padres gais, madres lesbianas o trans, o vivir la homoparentalidad, es poco común en la sociedad colombiana de provincia, como bien lo documentan los autores. Y de todas las opciones es más común la maternidad en mujeres con prácticas homoeróticas y la homoparentalidad femenina.

De otro lado, las trayectorias, duraciones y contextos del emparejamiento muestran un predominio del estilo de emparejamiento monoamoroso -monogámico- entre personas del mismo sexo, delimitando un conjunto de valores sociales relacionados con la exclusividad, el compromiso y la fidelidad sexual, aunque existe una diferenciación por género. Para el caso del eje cafetero, es llamativo cómo la experiencia de emparejamiento se ha constituido en una forma de vida compartida por ciertos grupos sociales, que impone una nueva agenda que transforma y subvierte la cultura sexual y el sistema sexo/género. En el estudio, los autores exploran los factores que explican la duración superior a un año de las relaciones de pareja del mismo sexo, encontrándose que la corresidencia actúa como cemento en las relaciones, al igual que el conocimiento de la relación por parte de la familia y la acumulación de la experiencia amorosa, que tiene un efecto biográfico en la vida de los y las encuestadas.

El texto contiene una traza rizomática profunda que está en correspondencia con la tesis y el objeto de conocimiento planteado, reconociendo el carácter interdisciplinario del tema. El desarrollo epistémico y metodológico del texto muestra la influencia de la filosofía, la socio-antropología, la demografía y los estudios críticos posestructuralistas para describir y comprender las prácticas homoeróticas entre hombres y entre mujeres en el eje cafetero. Es un ejercicio de alteridad a través del cual, como lo plantea Gallego (2010), se mira la realidad desde la perspectiva del otro haciendo tránsito por lo abyecto e impensable como contrapeso a lo pensable, lo inteligible y lo representable en la realidad.

Para finalizar, es un texto cuya lectura permite delimitar una serie de retos frente a la construcción de una agenda investigativa sobre homoparentalidad a nivel de país y continente, para los estudios interdisciplinares de familia:

1. La superación de la mirada satanizadora o paradisíaca de la experiencia homoparental con respecto a la crianza y cuidado de los hijos e hijas.

2. La necesidad de ampliar las comprensiones discursivas frente a la homoparentalidad desde la construcción de nuevas preguntas frente a las realidades que construyen estas familias. Por ejemplo, la homoparentalidad en la teoría del parentesco.

3. Necesidad de continuar fortaleciendo la investigación en parejas del mismo sexo desde un enfoque biográfico para construir y fortaceler una escuela de pensamiento con tradición, especificidad y disciplina en las ciencias sociales y humanas.

4. Consolidar un trabajo investigativo riguroso e innovador frente a la paternidad y maternidad homoparental, el cual no está adscrito al marco heterosexual y se consolida como una estructura familiar emergente.

5. Estudio de las acciones reivindicativas de grupos y colectivos sociales para poner fin a la discriminación y la violencia por razón de orientación sexual e identidad de género. 
Cada lector, desde sus equipajes culturales y experiencia académica, podrá dar una interpretación particular a cada uno de los temas abordados en los cinco capítulos que estructuran el libro, porque como lo señala Mélich, «si solo hay una interpretación, entonces ya no hay ninguna. La interpretación es infinita porque cada interpretación es finita. Y eso es la lectura, un juego de (in) finitas interpretaciones» (2015: 14).

Germán Darío Herrera Saray Docente-Investigador Departamento Estudios de Familia Universidad de Caldas (Manizales-Colombia) german.herrera@ucaldas.edu.co

\section{Referencias bibliográficas}

Beck, Ulrich; Beck-Gernsheim Elisabeth (2001). Las nuevas formas de la relación amorosa. Barcelona: Paidós.

Duch, Lluís; Mèlich Joan-Carles (2009). Ambigüedades del amor: antropología de la vida cotidiana 2/2. Barcelona: Editorial Trotta.

Gallego, M. Gabriel (2010). Demografía de lo otro. Iniciación sexual y trayectorias de emparejamiento entre varones en la ciudad de México. Ciudad de México: El Colegio de México.

Galvis, Adriana (2014). Representaciones sociales sobre el homoerotismo en prensa y literatura del Gran Caldas: 1920-1985. Tesis para optar al título de Magister en Estudios de Familia y Desarrollo, Departamento Estudios de Familia, Universidad de Caldas.

Gallego, M. Gabriel; Vasco Alzate, José Fernando (2017). «Vida doméstica en parejas del mismo sexo en ciudad de México y el Eje Cafetero colombiano». Revista Notas de Población, 105: 85-105.

Mélich, Joan-Carles (2015). La lectura como plegaria. Fragmentos filosóficos I. Barcelona: Fragmenta editorial. 